Research paper

\title{
Changes in national rates of psychiatric beds and incarceration in Central Eastern Europe and Central Asia from 1990-2019: A retrospective database analysis
}

\author{
Adrian P Mundt ${ }^{\mathrm{a}, *}$, Enzo Rozas Serri ${ }^{\mathrm{b}}$, Mathias Siebenförcher ${ }^{\mathrm{c}}$, Valbona Alikaj ${ }^{\mathrm{d}}$, \\ Fuad Ismayilove, Yury E Razvodovsky $^{\mathrm{f}}$, Mevludin Hasanovic ${ }^{\mathrm{g}}$, Petar Marinov ${ }^{\mathrm{h}}$, \\ Tanja Frančiškovići ${ }^{i}$ Pavla Cermakovaj, Jaanus Harro ${ }^{\mathrm{k}}$, Lela Sulaberidze ${ }^{\mathrm{l}}$, \\ Miklós Péter Kalapos ${ }^{\mathrm{m}}$, Marat Assimov ${ }^{\mathrm{n}}$, Saltanat Nurmagambetova ${ }^{\mathrm{o}}$, Nazmie F Ibishi $^{\mathrm{p}}$,
} Elena Molchanova ${ }^{\mathrm{q}}$, Māris Taube ${ }^{\mathrm{r}}$, Jana Chihai ${ }^{\mathrm{s}}$, Jovo Dedovic ${ }^{\mathrm{t}}$, Paweł Gosek ${ }^{\mathrm{u}}$, Nicoleta Tataru ${ }^{\mathrm{v}}$, Andrei Golenkov ${ }^{\mathrm{w}}$, Dusica Lecic-Tosevski ${ }^{\mathrm{x}}$, Dunja Randjelovic ${ }^{\mathrm{y}}$, Lubomira Izakova ${ }^{\mathrm{z}}$, Vesna Švab ${ }^{\mathrm{A}}$, Mutabara Vohidova ${ }^{\mathrm{B}}$, Nina Kerimi ${ }^{\mathrm{C}}$, Oleksii Sukhovii ${ }^{\mathrm{D}}$, Stefan Priebe $^{\mathrm{E}}$

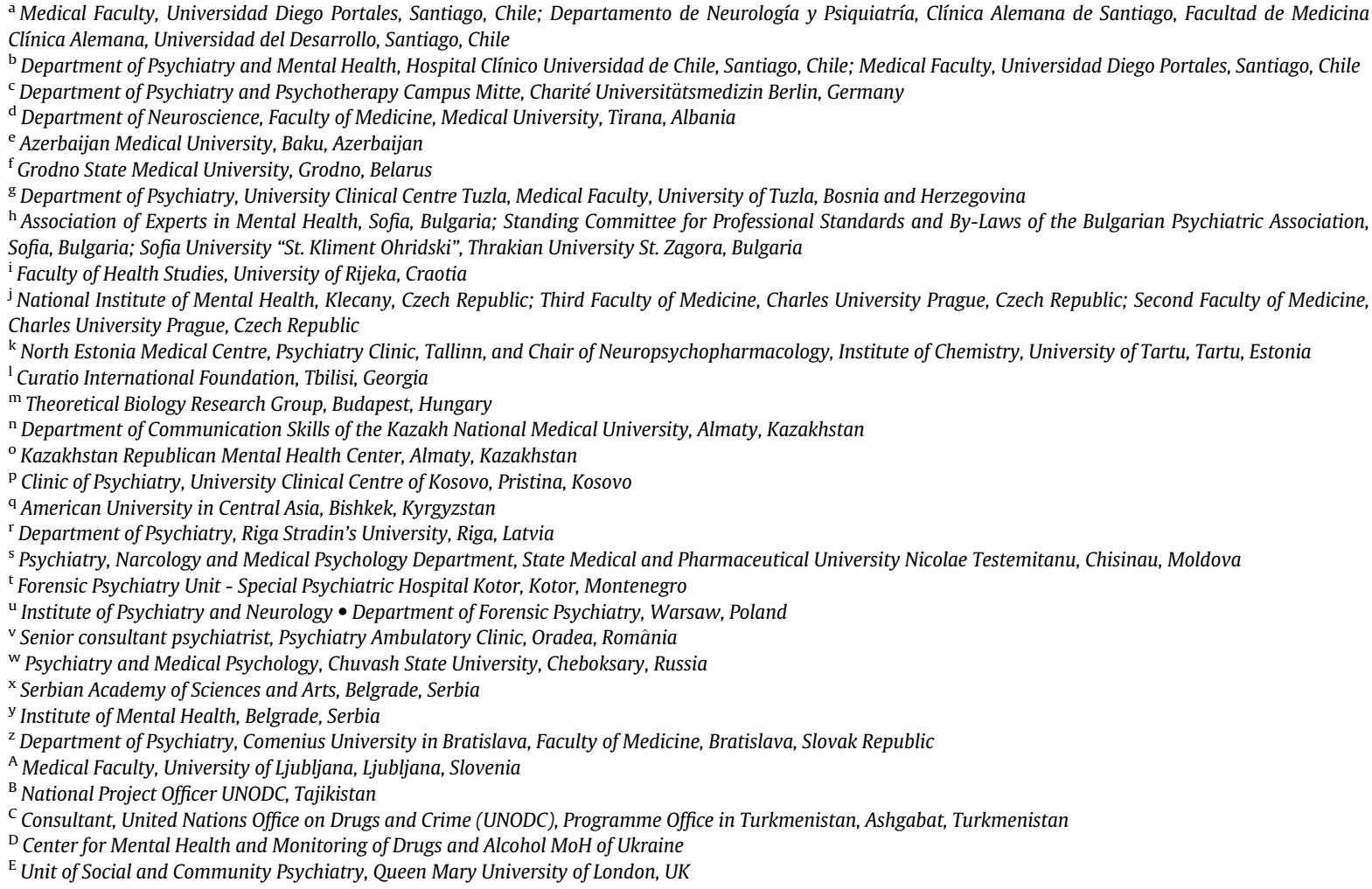

\section{A R T I C L E I N F O}

Article History:

Received 5 December 2020

\section{A B S T R A C T}

Background: Numbers of psychiatric beds (general, forensic, and residential) and prison populations have been considered to be indicators of institutionalisation of people with mental illnesses. The present study

\footnotetext{
* Corresponding author.

E-mail address: adrian.mundt@mail.udp.cl (A.P. Mundt).
} 
Revised 23 March 2021

Accepted 27 April 2021

Available online 5 June 2021 aimed to assess changes of those indicators across Central Eastern Europe and Central Asia (CEECA) over the last three decades to capture how care has developed during that historical period.

Methods: We retrospectively obtained data on numbers of psychiatric beds and prison populations from 30 countries in CEECA between 1990 and 2019. We calculated the median of the percent changes between the first and last available data points for all CEECA and for groups of countries based on former political alliances and income levels.

Findings: Primary national data were retrieved from 25 out of 30 countries. Data from international registries were used for the remaining five countries. For all of CEECA, the median decrease of the general psychiatric bed rates was 33•8\% between 1990 and 2019. Median increases were observed for forensic psychiatric beds $(24 \bullet 7 \%)$, residential facility beds $(12 \bullet 0 \%)$, and for prison populations $(36 \bullet 0 \%)$. Greater reductions of rates of psychiatric beds were observed in countries with lower per capita income as well as in countries that were formerly part of the Soviet Union. Seventeen out of 30 countries showed inverse trends for general psychiatric beds and prison populations over time, indicating a possible shift of institutionalisation towards correctional settings.

Interpretation: Most countries had decreased rates of general psychiatric beds, while there was an increase of forensic capacities. There was an increase in incarceration rates in a majority of countries. The large variation of changes underlines the need for policies that are informed by data and by comparisons across countries. Funding: Agencia Nacional de Investigación y Desarrollo in Chile, grant scheme FONDECYT Regular, grant number 1190613.

(C) 2021 The Authors. Published by Elsevier Ltd. This is an open access article under the CC BY-NC-ND license (http://creativecommons.org/licenses/by-nc-nd/4.0/)

\section{Introduction}

Central and Eastern Europe and Central Asia (CEECA) is a collection of 30 countries that have relevant economic, healthcare, political, and historical commonalities in the post-World War II period that merit consideration as a single geographic region. In health systems research, this region has also been referred to as Central Eastern Europe - Commonwealth of Independent States (CEE-CIS). The burden of mental and substance use disorders in CEECA is one of the highest in the world [1], with medium to high suicide rates [2,3], and an excess of alcohol [4] and illicit drug use disorders [5]. Additionally, older adults in Central and Eastern Europe have a higher prevalence of depressive symptoms and lower cognitive functions when compared to their counterparts in Western Europe and Scandinavia [6,7]. Political, economic, and social changes within CEECA have also given rise to transitions related to crime [8]-e.g., doubling of homicide rates in Russia in the 1990s-which contribute to sustained high incarceration rates [9]. Although some of countries in CEECA have shown substantial decreases in prison population rates in the last few years, 22 out of 30 exceed the world average (145 prisoners per 100000 population) [10].

Incarceration rates may also be considered as an indicator of institutionalization of mentally ill people, since mental health and substance use disorders are highly prevalent in prison populations worldwide $[11-15]$. They remain underestimated and undertreated, especially in low-income and middle-income countries (LMICs) [16,17]. Chronic infectious diseases [18] and injectable opioids addiction are further important health concerns in CEECA prisons [9]. Many individuals experience recurrent psychiatric hospitalizations and incarcerations over time-the so called revolving door phenomenom [19-21]. Repeated episodes of inpatient treatment and imprisonment have been reported for people with severe mental illness, comorbid substance use and personality disorders [22]. In 1939, Penrose described for the first time a possible inverse relationship between the number of psychiatric beds and the size of prison populations, based on a crosssectional analysis of data from 18 European countries [23]. This was addressed in a review including 21 publications between
1973 and 2015, of which, a majority supported the Penrose Hypothesis [24]. Although most studies in the review were from high-income countries (HICs) [25-31], and only a few studies have been conducted analyzing data from LMICs [26,32,33], the strongest evidence for an inverse relationship between the rates of psychiatric beds and incarceration rates was reported in Latin America [34]. The Penrose Hypothesis was partially supported by a study of 12 CEECA countries which showed decreasing trends for psychiatric bed rates in all countries between 1990 and 2009, and an increase in prison populations in half of the countries [33]. However, in Europe between 1993 and 2011, the effects of decreasing the number of psychiatric beds on prison populations were heterogeneous [25]. Since 1939, the populations in need of mental health beds may have shifted from those with chronic psychosis to people with substance use or dual disorders, depending on the region and advances in community psychiatry.

Until the dissolution of the Soviet Union in 1991, the mental health care system was linked with the political system in CEECA, and was almost exclusively based in large psychiatric hospitals [35-37]. People with substance use disorders were registered, which implied that treatments or imprisonment could be enforced [38]. Since then, the region has experienced developments in community and social psychiatry, human rights, stigma reduction, and mental health policies [39]. However, in a scoping review published in 2017 Central and Eastern Europe was considered a blind spot on the global mental health map [39], with services still predominantly based in psychiatric hospitals. In some countries, a substantial decrease in the number of general psychiatric hospital beds has been reported alongside an increase in supported housing capacities and forensic psychiatric beds [40], as well as increased numbers of social workers and clinical psychologists [41]. In other countries, however, essential psychiatric reforms have only recently been initiated or have yet to take place [42].

To inform further mental health system development and penal justice reforms, the assessment and trends of key indicators of institutionalization needs to be updated and put into a regional context. Therefore, the aim of the present study was to capture changes in rates of psychiatric beds and prison populations in all CEECA countries between 1990 and 2019. 


\section{Research in context}

\section{Evidence before this study}

While decreased numbers of psychiatric beds have been well documented and quantified for a range of high income countries, research from Central and Eastern Europe and Central Asia (CEECA; a grouping of 30 countries) is scarce. We conducted a search on PubMed using the term "psychiatric hospital beds", from database inception up to April 28, 2019, with no language restrictions. The result was a total of 1041 publications, of which, 333 reported (296 on a national level) bed numbers, bed capacities, occupancies, or correlations to deinstitutionalization. 203 studies reported data from European countries and 41 included low-income or middle-income countries. In addition, 144 articles were viewpoints, expert opinions and comments, or statistical models with recommendations for policies and planning of psychiatric services. Two studies quantified psychiatric bed removal in CEECA. The decrease in psychiatric beds was associated with increasing prison population rates in several studies. One study reported rates of psychiatric and forensic psychiatric hospital beds, rates of beds in supported housing facilities, and incarceration rates in 12 CEECA countries between 1990 and 2009. While all of the 12 countries reported a decrease in the rate of psychiatric beds, half of the countries also reported increased prison population rates. A second study quantified reduction in psychiatric beds in nine Eastern European countries between 1993 and 2011, of which, six reported increased prison populations in the same time period.

\section{Added value of this study}

This is an international collaborative work that compiles and quantifies data on general psychiatric, forensic and residential psychiatric beds and incarceration rates across 30 countries in CEECA. Most of these data were previously unpublished and not easily available and they will now be generally available. This contributes to promoting public health equity and will provide international perspectives for policy making within the CEECA region and worldwide. The participation in co-authorship of local researchers from 25 out of 30 included countries (most of them low- and middle-income economies) is especially relevant and reflects a diversity of professional background, gender, and geography.

\section{Implications of all the available evidence}

The large variation of changes across CEECA countries suggests that comparisons of policies and data across countries in a similar context may be a useful step towards developing appropriate policies. There is a need for policies informed by data given the high costs of institutional care. Policies should define targets for psychiatric bed rates to meet service needs in acute care and for residential bed rates to meet long-term care needs in the community. The increasing incarceration rates in a majority of the CEECA countries give rise to concern about institutionalization of individuals with mental health problems in correctional settings. Standardized data collection methods across countries and storage in unified data repositories could facilitate future comparative research.

\section{Methods}

\subsection{Definition of indicators}

We assessed four different indicators: (1) Psychiatric beds defined as any bed in hospital settings assigned to mental health treatment in psychiatric hospitals or in psychiatric units of general hospitals. This included beds specifically assigned to child and adolescent psychiatric care. (2) Forensic psychiatric beds included any bed reserved for the evaluation or treatment in forensic psychiatry ordered by courts of law. (3) Beds in residential or housing facilities for mentally ill people including non-hospital community-based mental health facilities that provide overnight residence, usually serving users with relatively stable mental disorders not requiring intensive medical interventions [43]. These facilities usually serve a variety of functions, and therefore, there was a variation in the terminology used for them [43-45]. We excluded facilities exclusively offering treatment for people with substance use disorders or intellectual disability, and generic facilities not intended to meet mental health needs (e.g., nursing and rest homes for elderly people, institutions treating neurological disorders or physical disability) [43]. 4) Prison populations were defined as all individuals confined day and night in jails or prison facilities as pre-trial detainees or convicted offenders.

\subsection{Data sources}

We contacted potential collaborators based on previous partnerships, scientific literature, snowballing, and personal contacts between May 24, and November 6, 2019. We also contacted Ministries of Health or related government institutions in countries where no collaborator could be engaged. A standardized template was used to collect data from every year for the time span between 1990 and 2019. Between May 29, 2019 and July 21, 2020, the data were collected by participating collaborators in the respective countries. When data from primary and secondary national sources were unavailable, data were retrieved from a previous study [33], from the European Health Information Gateway [46], and from the World Prison Brief online database [47]. Population counts, per capita gross national income (GNI), based on purchasing power parity in US dollars, and the Gini index, a measure of income inequality within a country, were retrieved from the World Bank [48]. Only for Ukraine in 2019, we used national population estimates excluding the occupied territories [49]. Although several countries in CEECA currently qualify as HIC, all of them were LMICs in 1990, the beginning of the observation period in this study.

\subsection{Statistical analysis}

Rates were calculated as the number of beds in the different types of institutions per 100000 population. We calculated the percentage changes of beds in psychiatric facilities and prison populations between the first and last available data points, and calculated the median and mean values with interquartile range, and 95\% confidence intervals of the means for these data points. In order to present a descriptive analysis of the percentage changes, we calculated the median and mean values and the 95\% confidence intervals of the means for percentage changes. Additionally, changes in absolute numbers of psychiatric beds and prison populations were calculated for all countries to estimate absolute changes in the region since 1990. Furthermore, we compared median and mean values for a priori defined groups by income level at the last data point and former 
political alliances (i.e., formerly part of the Soviet Union countries, or formerly part of Yugoslavia) and calculated percentage changes for the median and mean values over time. In regard to the Penrose Hypothesis, we compared a priori defined groups by their trends. Countries with decreasing rates of psychiatric beds and prison populations were compared to countries with inverse trends (decreasing rates of psychiatric beds and increasing rates of prison populations, in line with the Penrose Hypothesis). Findings from group comparisons were presented using descriptive analyses. We calculated interpolated mean rates for psychiatric beds and prison populations from the year 2000 onwards, when datasets for those indicators were most complete. Linear trend lines for both indicators and respective coefficients of determination were calculated. We compared findings for CEECA with countries forming part of the Organization for Economic Cooperation and Development (OECD) to put regional data in the context of current developments in high-income economies, for which data are publicly available. The OECD is an international organization of 37 countries, most of which are high-income economies. Numbers of psychiatric beds for OECD countries were retrieved from www.stats.oecd.org. Prison population rates of the OECD countries were retrieved from the Institute of Criminal Policy Research (www. prisonstudies.org) [47]. The Czech Republic, Estonia, Hungary, Latvia, Lithuania, Poland, Slovakia, Slovenia and Turkey form part of CEECA and the OECD.

\subsection{Role of the funding source}

The funder financed research assistance to coordinate the research network and data collection. The funding agency had no influence in the design of this study or in the analysis and interpretation of the data, nor in the writing or the decision to submit this article for publication.

\section{Results}

Primary data on rates of psychiatric beds and prison population were retrieved from 25 out of 30 countries in CEECA (Table 1). In the remaining five countries (Armenia, Lithuania, North Macedonia, Turkey, and Uzbekistan), we contacted at least one researcher, who either did not sustain contact or was unable to obtain the data. In these cases, data were retrieved from secondary sources. As of 2019, the populations of the participating countries amounted to more than 485 million inhabitants, of which the Russian Federation accounted for $30 \%$. 15 of the countries were former Soviet republics and seven were formerly part of Yugoslavia. Data on specialized forensic beds were obtained in 18 countries and on residential/housing facilities in 13 countries. For these two indicators, data were typically not available for the entire 1990-2019 period.

All countries included in this study were middle-income economies in the early 1990s. Belarus (upper middle), Kyrgyz Republic, Moldova, Ukraine, and Uzbekistan (lower middle) remained in the same income group from 1990 to 2019, and Tajikistan changed from lower middle-income to low-income level. The income group level of all other countries has increased, resulting in 10 (33\%) countries that had high-income economies by 2019. A list of the 30 CEECAC and the respective income group to which they belonged at the first and last data point, per capita GNI and Gini index are provided in the supplement (Supplement, Table 1).

\subsection{Psychiatric beds}

29 out of 30 countries reported decreased rates of psychiatric bed at the last data time point compared with the first (Fig. 1). Median percentage change was a decrease of 34\% (30 fewer beds per 100000 population), ranging from an increase in Kosovo (increase of $40 \%, 3.7$ more beds per 100000 population) to the greatest decrease in
Tajikistan (decrease of 77\%, 54 fewer beds per 100000 population). Despite the increased rate in Kosovo, both Tajikistan and Kosovo, alongside with Belarus and Turkey, reported the lowest psychiatric bed rates: all below 20 beds per 100000 population. The highest rates within the region were reported in Latvia, Lithuania, the Czech Republic, Croatia, and the Russian Federation: all above 90 beds per 100000 population (Table 1 ).

A total number of 444737 psychiatric beds were reported in CEECA at the first data time point, and 279739 remained at the last available data time point, indicating a decrease of 167998 psychiatric beds (decrease of $37 \%$ ) for the entire region. Greater decreases of rates of psychiatric beds were reported in countries that were formerly part of the Soviet Union, with more than twice the median percentage change compared to the other CEECA countries (Table 2).

Countries that were in the lower middle-income group in 2019 showed a greater decrease of median rates compared with upper middle-income and high-income economies in the same time period (Table 3).

Numbers of psychiatric beds used in specific subspecialties are reported in supplementary Table 2 .

\subsection{Prison populations}

Rates of prison populations increased in 18 countries, and decreased in 12 countries with a median increase of 36\% (50 more prisoners per 100000 population). This ranged from a decrease of 53\% (86 fewer per 100000 population) in Armenia to an increase of $629 \%$ (84 more per 100 000) in Kosovo (Fig. 2). Many countries that were formerly part of the Soviet Union, such as the Kyrgyz Republic, Latvia, Ukraine, and Uzbekistan, showed a decrease of over 35\% in prison populations from a high rate at the early time points during the period of observation. The greatest increase was seen in countries formerly part of Yugoslavia (Kosovo, Serbia, Croatia), Albania, the Czech Republic, and Turkey, all of which reported more than $145 \%$ increase in rates of prison populations from a low rate at the early time points during the period of observation. The median change in rates of prison populations between first and last data points was a $17 \%$ decrease in 15 post-Soviet republics, which contrasts with a $95 \%$ increase in all 15 remaining Eastern European countries, and over $115 \%$ increase in the seven countries that were formerly part of Yugoslavia. Rates of prison populations were decreased over the period of observation in lower middle-income countries, while they were increased in upper middle-income and high-income countries during the same time period.

\subsection{Specialized forensic psychiatric beds}

Rates of specialized forensic beds were reported by 18 out of 30 countries (Fig. 3). There was a median $24.7 \%$ increase (1.8 more beds per 100000 population) between the first and last data points for the entire region. For most countries (12 out of 18 ), we calculated increased rates of forensic beds. Bosnia and Herzegovina, Bulgaria, the Kyrgyz Republic, Romania, and Tajikistan had a decrease in rates, and the Slovak Republic reported no forensic psychiatric beds in the country at any time point in the period of observation (Table 2).

\subsection{Places in residential facilities}

Rates of beds in residential facilities were reported for only 13 countries (Fig. 4). Although Bulgaria reported a number of residential centers, no data for residential beds or places were available, so it was excluded from the analysis.

Large heterogeneity was seen for this indicator, with four countries (the Slovak Republic, Latvia, Hungary, and Croatia - in order of highest to lowest rate) reporting high rates ranging between 100 and more than 750 places per 100000 population at the last point of 
Rates of psychiatric beds, specialized forensic psychiatric beds, places in residential facilities for individuals with mental health problems, and prison populations in 30 Central Eastern European and Central Asian countries.

\begin{tabular}{|c|c|c|c|c|c|c|c|c|c|c|c|c|c|c|c|c|}
\hline & \multicolumn{4}{|c|}{ Psychiatric beds per 100000 population } & \multicolumn{4}{|c|}{$\begin{array}{l}\text { Specialized forensic psychiatric beds } \\
\text { per } 100000 \text { population }\end{array}$} & \multicolumn{4}{|c|}{$\begin{array}{l}\text { Beds in residential facilities } \\
\text { per } 100000 \text { population }\end{array}$} & \multicolumn{4}{|c|}{ Prison population per 100000 population } \\
\hline & $\begin{array}{l}\text { Period of } \\
\text { observation }\end{array}$ & $\begin{array}{l}\text { First data } \\
\text { point }\end{array}$ & $\begin{array}{l}\text { Last } \\
\text { data } \\
\text { point }\end{array}$ & $\begin{array}{l}\text { Percentage } \\
\text { change }\end{array}$ & $\begin{array}{l}\text { Period of } \\
\text { observation }\end{array}$ & $\begin{array}{l}\text { Rate } \\
\text { at first } \\
\text { point }\end{array}$ & $\begin{array}{l}\text { Rate } \\
\text { at last } \\
\text { point }\end{array}$ & $\begin{array}{l}\text { Percentage } \\
\text { change }\end{array}$ & $\begin{array}{l}\text { Period of } \\
\text { observation }\end{array}$ & $\begin{array}{l}\text { Rate } \\
\text { at first } \\
\text { point }\end{array}$ & $\begin{array}{l}\text { Rate } \\
\text { at last } \\
\text { point }\end{array}$ & $\begin{array}{l}\text { Percentage } \\
\text { change }\end{array}$ & $\begin{array}{l}\text { Period of } \\
\text { observation }\end{array}$ & $\begin{array}{l}\text { Rate } \\
\text { at first } \\
\text { point }\end{array}$ & $\begin{array}{l}\text { Rate } \\
\text { at last } \\
\text { point }\end{array}$ & $\begin{array}{l}\text { Percentage } \\
\text { change }\end{array}$ \\
\hline Albania & $1990-2018$ & $38 \bullet 6$ & $26 \bullet 0$ & $-32 \cdot 7$ & 2004-2019 & $1 \bullet 9$ & $9 \bullet 5$ & $404 \bullet 8$ & 2002-2019 & $0 \bullet 4$ & $4 \bullet 9$ & 1167 & $1995-2019$ & $36 \bullet 5$ & $179 \bullet 1$ & $390 \bullet 7$ \\
\hline Armenia & $1990-2014$ & $61 \bullet 6$ & $50 \bullet 4$ & $-18 \cdot 2$ & NA & $\bullet$ & $\bullet$ & NA & NA & $\bullet$ & $\bullet$ & NA & $1994-2019$ & $163 \bullet 0$ & $76 \bullet 6$ & $-53 \bullet 0$ \\
\hline Azerbaijan & $1991-2018$ & $73 \bullet 9$ & $39 \cdot 2$ & $-46 \bullet 9$ & $1990-2017$ & $1 \bullet 0$ & $1 \bullet 8$ & $86 \bullet 7$ & $1991-2018$ & $11 \bullet 1$ & $8 \bullet 8$ & $-21 \bullet 0$ & $1997-2018$ & $317 \bullet 1$ & $234 \bullet 6$ & $-26 \bullet 0$ \\
\hline Belarus & $1990-2013$ & $44 \bullet 1$ & $18 \bullet 0$ & $-59 \cdot 2$ & NA & •• & $\bullet$ & $\mathrm{NA}$ & NA & $\bullet$ & $\bullet$ & NA & $1990-2018$ & $240 \bullet 6$ & $342 \bullet 4$ & $42 \cdot 3$ \\
\hline Bosnia-Herzegovina & $1992-2018$ & $66 \bullet 7$ & $35 \bullet 7$ & $-46 \bullet 4$ & $1992-2018$ & $14 \cdot 2$ & $6 \bullet 0$ & $-57 \bullet 7$ & NA & •• & .• & NA & $1998-2014$ & $41 \cdot 4$ & $76 \cdot 5$ & $84 \bullet 8$ \\
\hline Bulgaria & $1990-2016$ & $92 \bullet 9$ & $56 \bullet 9$ & $-38 \bullet 7$ & $1990-2016$ & $0 \bullet 7$ & $0 \bullet 3$ & $-59 \bullet 4$ & NA & •• & •• & NA & $1990-2014$ & $126 \cdot 5$ & $108 \cdot 9$ & $-13 \bullet 9$ \\
\hline Croatia & $1997-2017$ & $104 \bullet 2$ & $94 \bullet 1$ & $-9 \bullet 6$ & $1998-2019$ & $7 \bullet 7$ & $8 \bullet 8$ & $13 \bullet 4$ & $2007-2017$ & $89 \bullet 7$ & $100 \bullet 4$ & $12 \bullet 0$ & $1990-2018$ & $31 \bullet 8$ & $78 \bullet 0$ & $145 \bullet 5$ \\
\hline Czech Republic & $1990-2017$ & $140 \bullet 4$ & $94 \bullet 6$ & $-32 \bullet 6$ & NA & $\bullet$ & $\bullet$ & NA & NA & $\bullet$ & $\bullet$ & NA & $1990-2019$ & $79 \bullet 7$ & $198 \bullet 4$ & $149 \bullet 1$ \\
\hline Estonia & $1994-2018$ & $108 \bullet 4$ & $54 \cdot 3$ & $-49 \bullet 9$ & $1992-2019$ & $2 \bullet 0$ & $6 \bullet 0$ & $207 \bullet 7$ & 2003-2018 & $41 \cdot 2$ & $85 \cdot 2$ & $106 \bullet 6$ & $1992-2019$ & $287 \cdot 5$ & $194 \bullet 8$ & $-32 \cdot 3$ \\
\hline Georgia & 1996-2018 & $40 \cdot 5$ & $31 \bullet 9$ & $-21 \bullet 3$ & NA & $\bullet$ & $\bullet$ & NA & 1990-2019 & $0 \bullet 0$ & $0 \bullet 0$ & $0 \bullet 0$ & $1994-2018$ & $152 \bullet 5$ & $256 \bullet 6$ & $68 \bullet 3$ \\
\hline Hungary & $1990-2017$ & $133 \bullet 0$ & $87 \cdot 4$ & $-34 \bullet 3$ & $1990-2017$ & $1 \bullet 4$ & $1 \bullet 9$ & $34 \bullet 0$ & $1993-2018$ & $206 \bullet 5$ & $260 \bullet 0$ & $25 \bullet 9$ & $1990-2018$ & $118 \bullet 8$ & $177 \cdot 2$ & $49 \cdot 2$ \\
\hline Kazakhstan & $1990-2018$ & $90 \bullet 8$ & $44 \bullet 1$ & $-51 \bullet 4$ & NA & $\bullet$ & $\bullet$ & NA & NA & $\bullet$ & $\bullet$ & NA & $1990-2019$ & $338 \bullet 6$ & $211 \bullet 8$ & $-37 \bullet 4$ \\
\hline Kosovo & $1990-2019$ & $9 \bullet 2$ & $12 \bullet 9$ & $39 \bullet 9$ & $1990-2019$ & $0 \bullet 2$ & $2 \bullet 0$ & 1017 & $1990-2019$ & $16 \bullet 1$ & $13 \bullet 7$ & $-15 \bullet 3$ & $2000-2019$ & $13 \bullet 4$ & $97 \cdot 3$ & $628 \cdot 5$ \\
\hline Kyrgyz Republic & $1990-2018$ & $87 \bullet 8$ & $24 \bullet 6$ & $-72 \bullet 0$ & $1995-2018$ & $2 \bullet 3$ & $1 \bullet 6$ & $-31 \cdot 3$ & NA & $\bullet$ & $\bullet$ & NA & $1990-2018$ & $195 \bullet 9$ & $112 \bullet 4$ & $-42 \cdot 7$ \\
\hline Latvia & $1990-2018$ & $260 \bullet 4$ & $122 \cdot 5$ & $-53 \bullet 0$ & NA & $\bullet$ & $\bullet$ & NA & $1995-2018$ & $430 \bullet 7$ & $673 \cdot 3$ & $56 \bullet 3$ & $1990-2018$ & $327 \bullet 7$ & $182 \bullet 8$ & $-44 \cdot 2$ \\
\hline Lithuania & $1990-2014$ & $164 \bullet 8$ & $107 \bullet 9$ & $-34 \cdot 5$ & $\mathrm{NA}$ & $\bullet$ & $\bullet$ & NA & NA & $\bullet$ & $\bullet$ & NA & $1990-2018$ & $232 \bullet 2$ & $235 \bullet 5$ & $1 \bullet 4$ \\
\hline Moldova & $1990-2018$ & $146 \bullet 4$ & $38 \cdot 3$ & $-73 \bullet 9$ & $2004-2018$ & $3 \bullet 4$ & $4 \bullet 0$ & $15 \bullet 4$ & 2014-2018 & $1 \cdot 5$ & $1 \bullet 9$ & $26 \bullet 3$ & $1991-2018$ & $253 \bullet 6$ & $226 \bullet 7$ & $-10 \bullet 6$ \\
\hline Montenegro & $1990-2014$ & $63 \cdot 7$ & $49 \bullet 4$ & $-22 \bullet 4$ & $1990-2019$ & $0 \bullet 0$ & $3 \bullet 4$ & NA & $1990-2019$ & $0 \bullet 0$ & $0 \bullet 0$ & $0 \bullet 0$ & $2000-2016$ & $109 \bullet 8$ & $180 \cdot 5$ & $64 \bullet 4$ \\
\hline North Macedonia & $1990-2013$ & $81 \cdot 4$ & $54 \cdot 3$ & $-33 \cdot 2$ & NA & $\bullet$ & $\bullet$ & NA & NA & $\bullet$ & $\bullet$ & NA & $1990-2019$ & $78 \cdot 6$ & $90 \cdot 2$ & $14 \cdot 7$ \\
\hline Poland & $1990-2018$ & $96 \bullet 0$ & $64 \bullet 0$ & $-33 \cdot 3$ & $2001-2018$ & $3 \bullet 9$ & $6 \bullet 9$ & $77 \cdot 2$ & NA & $\bullet$ & $\bullet$ & NA & $1990-2018$ & $131 \bullet 6$ & $190 \bullet 1$ & $44 \cdot 4$ \\
\hline Romania & $1990-2018$ & $95 \bullet 4$ & $80 \bullet 4$ & $-15 \bullet 7$ & $2010-2018$ & $4 \bullet 8$ & $6 \bullet 5$ & $36 \bullet 3$ & NA & .• & .• & NA & $1990-2018$ & $112 \bullet 1$ & $106 \bullet 8$ & $-4 \bullet 8$ \\
\hline Russian Federation & $1992-2017$ & $129 \bullet 2$ & $90 \bullet 9$ & $-29 \bullet 7$ & $1992-2017$ & $4 \bullet 6$ & $4 \bullet 7$ & $1 \bullet 1$ & NA & $\bullet$ & $\bullet$ & NA & $1990-2017$ & $471 \cdot 3$ & $435 \bullet 9$ & $-7 \cdot 5$ \\
\hline Serbia & $1990-2019$ & $77 \bullet 8$ & $71 \cdot 6$ & $-7 \bullet 9$ & $1990-2018$ & $5 \bullet 3$ & $7 \bullet 9$ & $49 \cdot 5$ & $1990-2019$ & $0 \bullet 0$ & $0 \bullet 0$ & $0 \bullet 0$ & $1990-2018$ & $47 \bullet 8$ & $155 \cdot 7$ & $226 \bullet 1$ \\
\hline Slovak Republic & 2006-2017 & $84 \bullet 0$ & $81 \cdot 5$ & $-3 \bullet 0$ & $1990-2019$ & $0 \bullet 0$ & $0 \bullet 0$ & $0 \bullet 0$ & $2005-2017$ & $545 \bullet 6$ & $753 \bullet 6$ & $38 \bullet 1$ & $1990-2018$ & $86 \bullet 6$ & $189 \bullet 0$ & $118 \bullet 1$ \\
\hline Slovenia & $1990-2018$ & $80 \bullet 8$ & $65 \bullet 8$ & $-18 \cdot 5$ & $1990-2018$ & $0 \bullet 0$ & $2 \bullet 3$ & NA & 2009-2018 & $11 \bullet 6$ & $11 \bullet 0$ & $-5 \bullet 1$ & $1990-2018$ & $41 \bullet 9$ & $65 \bullet 5$ & $56 \bullet 1$ \\
\hline Tajikistan & $1990-2019$ & $70 \bullet 1$ & $16 \bullet 1$ & $-77 \bullet 0$ & $1990-2019$ & $0 \bullet 9$ & $0 \bullet 3$ & $-71 \bullet 7$ & NA & $\bullet$ & •• & NA & $1993-2010$ & $75 \bullet 1$ & $123 \bullet 8$ & $64 \cdot 7$ \\
\hline Turkey & $2000-2014$ & $5 \bullet 7$ & $5 \cdot 5$ & $-4 \bullet 0$ & NA & $\bullet$ & $\bullet$ & NA & NA & $\bullet$ & $\bullet$ & NA & $1990-2019$ & $84 \cdot 6$ & $342 \bullet 8$ & $305 \bullet 3$ \\
\hline Turkmenistan & $1990-2017$ & $76 \bullet 7$ & $27 \bullet 9$ & $-63 \bullet 6$ & NA & $\bullet$ & $\bullet$ & NA & NA & $\bullet$ & •• & NA & $1998-2017$ & $407 \bullet 8$ & $528 \bullet 9$ & $29 \bullet 7$ \\
\hline Ukraine & $1990-2019$ & $134 \bullet 4$ & $73 \cdot 1^{*}$ & $-45 \bullet 6$ & NA & $\bullet$ & $\bullet$ & NA & NA & $\bullet$ & $\bullet$ & NA & $1990-2019$ & $224 \bullet 3$ & $141 \bullet 8^{*}$ & $-36 \bullet 8$ \\
\hline Uzbekistan & $1990-2014$ & $60 \bullet 0$ & $24 \bullet 3$ & $-59 \cdot 5$ & NA & $\bullet$ & $\bullet$ & NA & NA & •• & $\bullet$ & NA & $1996-2014$ & $258 \bullet 3$ & $142 \bullet 7$ & $-44 \bullet 8$ \\
\hline Median & & $82 \bullet 7$ & $52 \bullet 4$ & $-33 \bullet 8$ & & $1 \bullet 9$ & $3 \bullet 7$ & $24 \cdot 7$ & & $11 \bullet 6$ & $11 \bullet 0$ & $12 \bullet 0$ & & $129 \bullet 1$ & $179 \bullet 8$ & $36 \bullet 0$ \\
\hline IQR & & $42 \bullet 9$ & $49 \cdot 7$ & $31 \bullet 8$ & & $3 \bullet 7$ & $4 \bullet 6$ & $87 \bullet 4$ & & $89 \bullet 3$ & $98 \cdot 5$ & $38 \bullet 1$ & & $171 \bullet 4$ & $113 \cdot 2$ & $103 \cdot 7$ \\
\hline Mean & & $90 \bullet 6$ & $54 \bullet 8$ & $-34 \bullet 9$ & & $3 \bullet 0$ & $4 \bullet 1$ & $107 \bullet 7$ & & $104 \cdot 2$ & $147 \bullet 1$ & $107 \bullet 0$ & & $169 \bullet 6$ & $189 \bullet 4$ & $71 \bullet 0$ \\
\hline Upper 95\% CI & & $108 \cdot 3$ & $65 \bullet 8$ & $-26 \bullet 0$ & & $4 \bullet 6$ & $5 \bullet 5$ & $232 \bullet 1$ & & $202 \bullet 8$ & $289 \bullet 6$ & $281 \bullet 1$ & & $213 \bullet 0$ & $227 \bullet 8$ & $124 \bullet 2$ \\
\hline Lower $95 \% \mathrm{CI}$ & & $72 \bullet 9$ & $43 \bullet 8$ & $-43 \bullet 8$ & & $1 \cdot 4$ & $2 \cdot 7$ & $-16 \bullet 7$ & & $5 \bullet 6$ & $4 \bullet 6$ & $-67 \bullet 1$ & & $126 \bullet 2$ & $151 \bullet 0$ & $17 \bullet 8$ \\
\hline $\begin{array}{l}\text { Absolute numbers } \\
\text { (thousands) }\end{array}$ & & $444 \bullet 7$ & $279 \bullet 7$ & $-37 \bullet 1$ & & $11 \bullet 4$ & $12 \bullet 9$ & $12 \bullet 7$ & & $69 \bullet 8$ & $85 \bullet 8$ & $23 \bullet 0$ & & 1,225 & 1,363 & $11 \bullet 3$ \\
\hline $\begin{array}{l}\text { Total population } \\
\text { (millions) }\end{array}$ & & $474 \bullet 2$ & $486 \bullet 6$ & $2 \bullet 6$ & & $272 \bullet 9$ & $276 \bullet 4$ & $1 \bullet 3$ & & $54 \bullet 7$ & $54 \bullet 1$ & $-1 \bullet 1$ & & $468 \bullet 1$ & $491 \bullet 4$ & $5 \bullet 0$ \\
\hline Number of countries & & 30 & 30 & & & 18 & 18 & & & 13 & 13 & & & 30 & 30 & \\
\hline
\end{tabular}

NA. not applicable. IQR. Interquartile range; CI. Confidence interval of the mean.

$*$ Rates of psychiatric beds and prisoner populations excluded the occupied territories for the year 2019. 

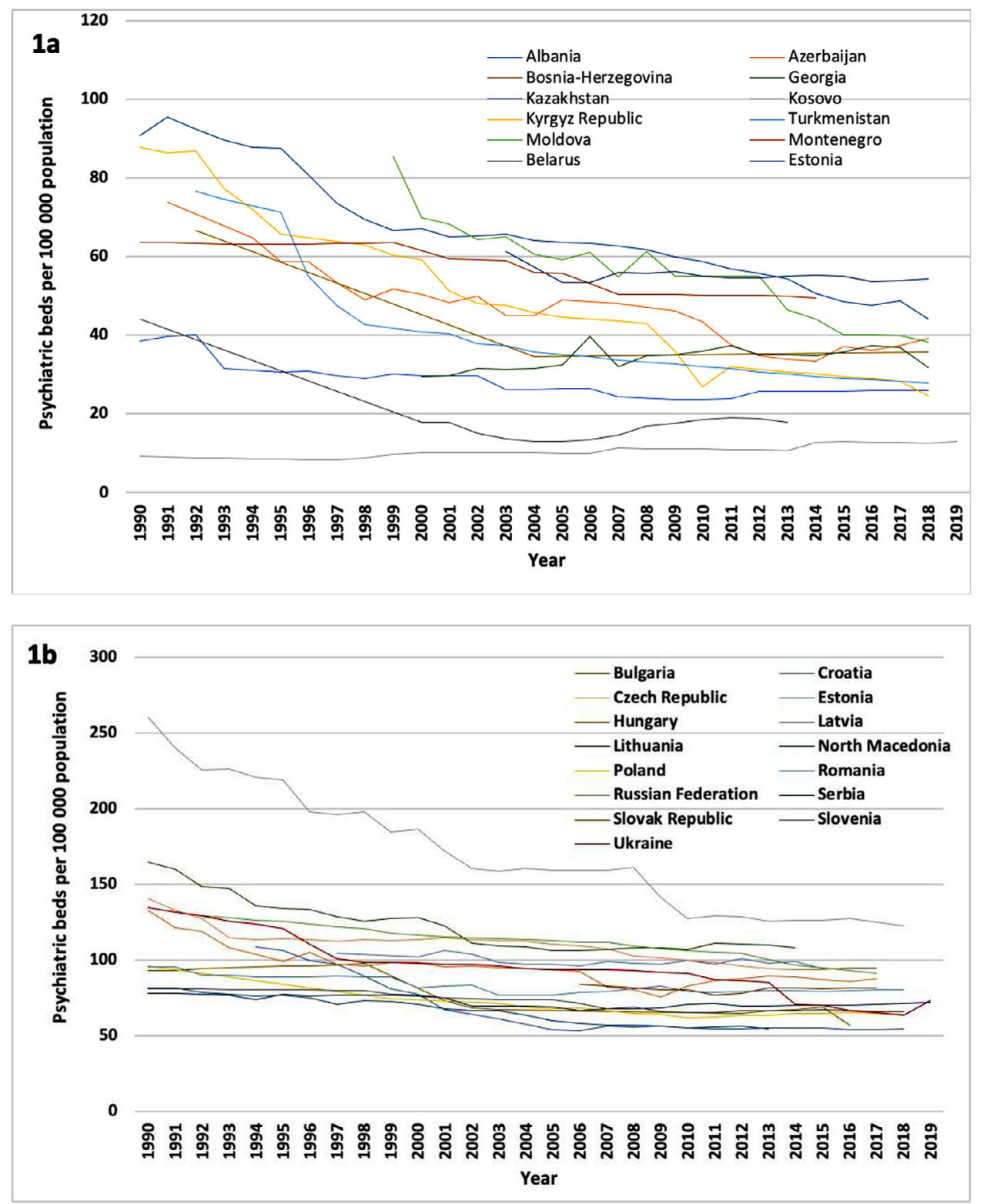

Fig. 1. Rates of psychiatric beds per 100000 population (1990-2019). a) Countries with rates lower than 54 per 100000 population (at the last data point); b) Countries with rates higher than 54 per 100000 population (at the last data point).

observation. The remaining nine countries provided between zero (Georgia, Montenegro, and Serbia) and 85 (Estonia) places per 100 000 population at the last point of observation. Seven countries (Albania, Croatia, Estonia, Hungary, Latvia, Moldova, and the Slovak Republic) reported increasing rates of beds in residential facilities, and three (Azerbaijan, Kosovo and Slovenia) reported decreasing rates over the period of observation (Table 2). Georgia and Serbia did not provide any places in residential facilities over the entire time span. Data on psychiatric residential beds were mainly reported by high-income countries. In most middle-income countries, data were unavailable.

\subsection{Penrose hypothesis}

Seventeen out of 30 countries (Albania, Belarus, Bosnia and Herzegovina, Croatia, the Czech Republic, Georgia, Hungary, Lithuania, Montenegro, North Macedonia, Poland, Serbia, the Slovak Republic, Slovenia, Tajikistan, Turkey, and Turkmenistan) showed an inverse trend between rates of psychiatric beds and rates of prison populations in support of the Penrose Hypothesis: while rates of psychiatric beds decreased, the rates of individuals in prisons increased. Within CEECA, none of the countries had inversely increasing rates psychiatric beds and decreasing prison populations.

Twelve countries (Armenia, Azerbaijan, Bulgaria, Estonia, Kazakhstan, the Kyrgyz Republic, Latvia, Moldova, Romania, Russian Federation, Ukraine, and Uzbekistan) reported decreases in both psychiatric bed rates and prison population rates. Kosovo was the only country with increasing rates of both indicators.

Comparisons between the group of countries with inverse trends between indicators (psychiatric beds and prison populations) and the group with decreasing trends of indicators are shown in Table 4. Countries with decreasing trends had the highest rates of prisoners at beginning of the observation period. Most of those countries were formerly part of the Soviet Union, which had very high prison population rates at the time of dissolution. Neither the GNI or Gini index substantially differed between these groups. 


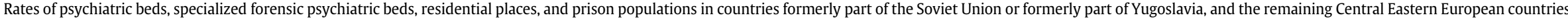

\begin{tabular}{|c|c|c|c|c|c|c|c|c|c|c|c|c|}
\hline & \multicolumn{3}{|c|}{ Psychiatric beds per 100000 population } & \multicolumn{3}{|c|}{ Specialized forensic beds per 100000 population } & \multicolumn{3}{|c|}{ Beds in residential facilities per 100000 population } & \multicolumn{3}{|c|}{ Prison population per 100000 population } \\
\hline & $\begin{array}{l}\text { First data } \\
\text { point }\end{array}$ & $\begin{array}{l}\text { Last data } \\
\text { point }\end{array}$ & $\begin{array}{l}\text { Percentage } \\
\text { change }\end{array}$ & $\begin{array}{l}\text { Rate at first } \\
\text { point }\end{array}$ & $\begin{array}{l}\text { Rate at last } \\
\text { point }\end{array}$ & $\begin{array}{l}\text { Percentage } \\
\text { change }\end{array}$ & $\begin{array}{l}\text { Rate at first } \\
\text { point }\end{array}$ & $\begin{array}{l}\text { Rate at last } \\
\text { point }\end{array}$ & $\begin{array}{l}\text { Percentage } \\
\text { change }\end{array}$ & $\begin{array}{l}\text { Rate at first } \\
\text { point }\end{array}$ & $\begin{array}{l}\text { Rate at last } \\
\text { point }\end{array}$ & $\begin{array}{l}\text { Percentage } \\
\text { change }\end{array}$ \\
\hline \multicolumn{13}{|c|}{$\begin{array}{l}\text { Countries formerly part of } \\
\text { Soviet Union* }\end{array}$} \\
\hline Median & $87 \bullet 8$ & $39 \cdot 2$ & $-55 \bullet 3$ & $2 \bullet 1$ & $2 \bullet 9$ & $36 \bullet 2$ & $11 \bullet 1$ & $8 \bullet 8$ & $-21 \bullet 0$ & $253 \bullet 6$ & $211 \bullet 8$ & $-16 \bullet 5$ \\
\hline Mean values & $103 \bullet 3$ & $50 \bullet 9$ & $-50 \bullet 7$ & $2 \bullet 4$ & $3 \bullet 1$ & $28 \bullet 8$ & $96 \bullet 9$ & $153 \bullet 8$ & $58 \bullet 7$ & $263 \bullet 0$ & $229 \bullet 8$ & $-12 \bullet 6$ \\
\hline Number of countries & 15 & 15 & & 6 & 6 & & 5 & 5 & & 15 & 15 & \\
\hline \multicolumn{13}{|c|}{$\begin{array}{l}\text { Countries formerly part of } \\
\text { Yugoslavia }\end{array}$} \\
\hline Median & $77 \bullet 8$ & $54 \bullet 3$ & $-30 \bullet 1$ & $2 \bullet 7$ & $4 \bullet 7$ & $72 \bullet 1$ & $11 \bullet 6$ & $11 \bullet 0$ & $-5 \bullet 1$ & $41 \bullet 9$ & $90 \bullet 2$ & $115 \bullet 0$ \\
\hline Mean values & $69 \bullet 1$ & $54 \bullet 9$ & $-20 \bullet 6$ & $4 \bullet 6$ & $5 \bullet 1$ & $11 \bullet 0$ & $23 \cdot 5$ & $25 \bullet 0$ & $6 \bullet 5$ & $52 \bullet 1$ & $106 \bullet 2$ & $103 \bullet 9$ \\
\hline Number of countries & 7 & 7 & & 6 & 6 & & 5 & 5 & & 7 & 7 & \\
\hline \multicolumn{13}{|c|}{$\begin{array}{l}\text { Remaining Central and Eastern } \\
\text { European countries }\end{array}$} \\
\hline Median & $81 \bullet 4$ & $64 \bullet 0$ & $-21 \cdot 3$ & $1 \bullet 6$ & $4 \bullet 7$ & $185 \bullet 1$ & $13 \bullet 9$ & $12 \bullet 3$ & $-11 \bullet 0$ & $79 \bullet 7$ & $155 \bullet 7$ & $95 \bullet 5$ \\
\hline Mean values & $78 \bullet 0$ & $58 \bullet 7$ & $-24 \cdot 7$ & $3 \bullet 3$ & $4 \bullet 6$ & $38 \bullet 6$ & $108 \bullet 7$ & $143 \bullet 0$ & $31 \cdot 5$ & $76 \bullet 1$ & $149 \bullet 1$ & $96 \bullet 0$ \\
\hline Number of countries & 15 & 15 & & 12 & 12 & & 8 & 8 & & 15 & 15 & \\
\hline
\end{tabular}

* Armenia, Azerbaijan, Belarus, Estonia, Georgia, Kazakhstan, Kyrgyz Republic, Latvia, Lithuania, Moldova, Russian Federation, Tajikistan, Turkmenistan, Ukraine, Uzbekistan

** Bosnia and Herzegovina, Croatia, Kosovo, Montenegro, North Macedonia, Serbia, Slovenia;

*** Albania, Bosnia and Herzegovina, Bulgaria, Croatia, Czech Republic, Hungary, Kosovo, Montenegro, North Macedonia, Poland, Romania, Serbia, Slovak Republic, Slovenia, Turkey.

Table 3

Median rates of psychiatric beds, specialized forensic psychiatric beds, places in residential facilities for people with mental health problems, and prison populations by income group in 2019 in Central Eastern Europe and Central Asia.

\begin{tabular}{|c|c|c|c|c|c|c|c|c|c|c|c|c|}
\hline & \multicolumn{3}{|c|}{ Psychiatric beds per 100000 population } & \multicolumn{3}{|c|}{ Specialized forensic beds per 100000 population } & \multicolumn{3}{|c|}{ Beds in residential facilities per 100000 population } & \multicolumn{3}{|c|}{ Prison population per 100000 population } \\
\hline & $\begin{array}{l}\text { First data } \\
\text { point }\end{array}$ & $\begin{array}{l}\text { Last data } \\
\text { point }\end{array}$ & $\begin{array}{l}\text { Percentage } \\
\text { change }\end{array}$ & $\begin{array}{l}\text { Rate at first } \\
\text { point }\end{array}$ & $\begin{array}{l}\text { Rate at last } \\
\text { point }\end{array}$ & $\begin{array}{l}\text { Percentage } \\
\text { change }\end{array}$ & $\begin{array}{l}\text { Rate at first } \\
\text { point }\end{array}$ & $\begin{array}{l}\text { Rate at last } \\
\text { point }\end{array}$ & $\begin{array}{l}\text { Percentage } \\
\text { change }\end{array}$ & $\begin{array}{l}\text { Rate at first } \\
\text { point }\end{array}$ & $\begin{array}{l}\text { Rate at last } \\
\text { point }\end{array}$ & $\begin{array}{l}\text { Percentage } \\
\text { change }\end{array}$ \\
\hline Lower middle* $^{*}$ & 87.8 & 24.6 & -72.0 & 2.3 & 1.6 & -31.3 & NA & NA & NA & 224.3 & 141.8 & -36.8 \\
\hline Number of countries & 5 & 5 & & 3 & 3 & & 1 & 1 & & 5 & 5 & \\
\hline Upper middle $^{* *}$ & 66.7 & 39.2 & -41.2 & 1.4 & 4.0 & 181.5 & 0.2 & 2.5 & 1166.7 & 126.5 & 180.5 & 42.6 \\
\hline Number of countries & 15 & 15 & & 8 & 8 & & 6 & 6 & & 15 & 15 & \\
\hline High $^{* *+}$ & 106.3 & 84.4 & -20.6 & 2.0 & 6.0 & 207.7 & 148.1 & 180.2 & 21.7 & 115.4 & 185.9 & 61.1 \\
\hline Number of countries & 10 & 10 & & 7 & 7 & & 6 & 6 & & 10 & 10 & \\
\hline
\end{tabular}

* Kyrgyz Republic, Moldova, Tajikistan, Ukraine, Uzbekistan;

* Albania, Armenia, Azerbaijan, Belarus, Bosnia and Herzegovina, Bulgaria, Georgia, Kazakhstan, Kosovo, Montenegro, North Macedonia, Russian Federation, Serbia, Turkey; Turkmenistan;

*** Croatia, Czech Republic, Estonia, Hungary, Latvia, Lithuania, Poland Romania, Slovak Republic, Slovenia. 

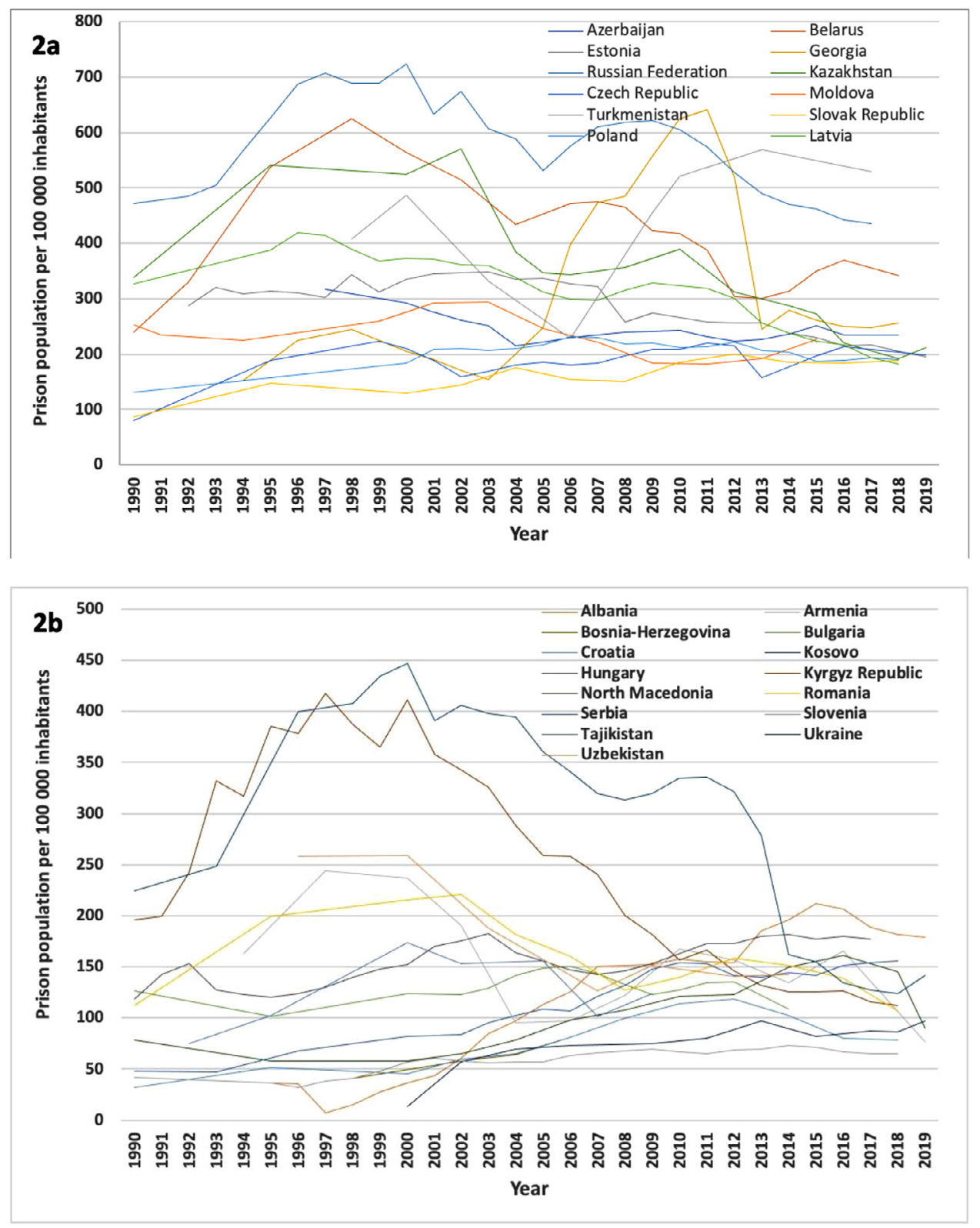

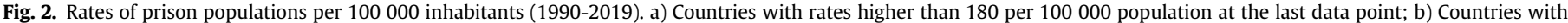
rates lower than 180 per 100000 population at the last data point.

The mean psychiatric bed rates from the year 2000 onwards showed a decreasing trend (slope: -0.79 ) that was slower than the mean decrease in OECD countries and on a lower level. The mean prison population rates also showed a decreasing trend (slope: $-1 \bullet 89$ ), contrasting the OECD in the same time period that showed on average an increasing trend (Fig. 5). However, prison population rates in CEECA remained on a higher level than in the OECD countries.

\section{Discussion}

\subsection{Main findings}

In the period of observation between 1990 and 2019, CEECA underwent major and inconsistent changes in institutionalized care. There was a substantial decrease of rates of psychiatric beds. These decreases were especially pronounced in the lower-middle income economies. Twelve countries of the region reported decreasing trends for both rates of prison populations and psychiatric beds, whereas 17 countries reported decreased psychiatric bed rates, while prison population rates increased.

\subsection{Interpretation}

Over three decades following major political changes in the region, a large part of CEECA underwent a sustained process of decreasing the number of psychiatric beds, which was in line with mental health system reforms towards more decentralized outpatient treatments. Median rates across CEECA approached the value of 50 per 100000 population in 2019, which was estimated as a minimum number for the public mental health care system by the Treatment Advocacy Centre in the US [50], below the average of 71 per 10000 in OECD countries [51]. However, rates of psychiatric beds in CEECA remained markedly higher than in other LMIC regions, such as Latin America [34]. Increased rates of specialized forensic psychiatric beds and residential facilities for mentally ill individuals was observed in several participating countries. Although the absolute 


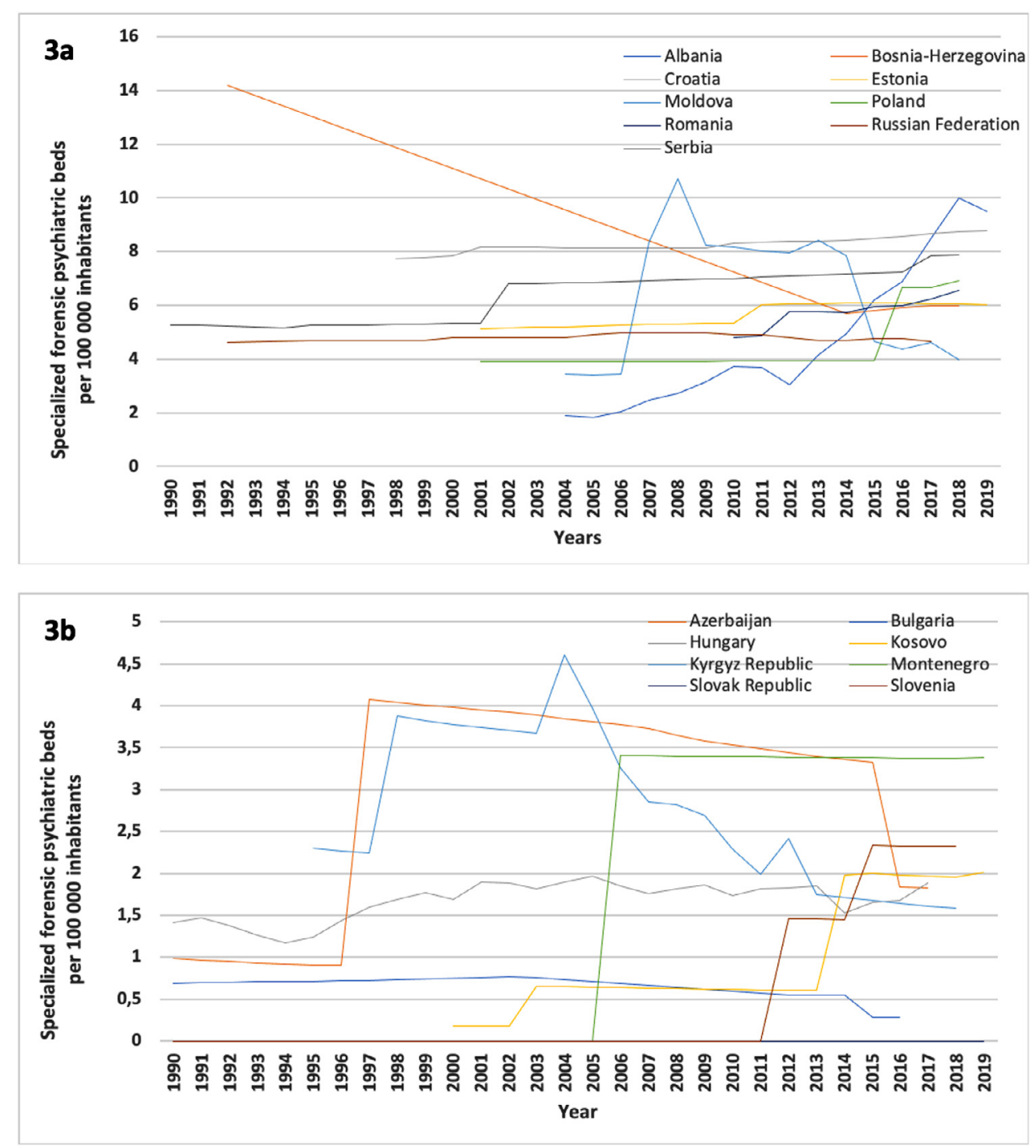

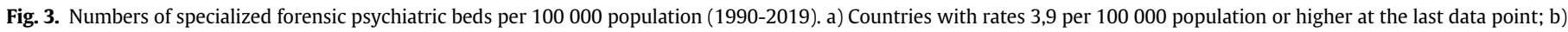
Countries with rates lower than 3,9 per 100000 population at the last data point.

numbers of psychiatric beds increased in Turkey, the country exhibited a decreasing trend in rates of psychiatric beds per 100000 population. Compared to the rest of the region, Turkey had the lowest psychiatric bed rate at the first and the last data points, which were more similar to countries of the eastern Mediterranean region [52,53]. Russia and Turkmenistan reported data for so called narcological beds, which were excluded from psychiatric bed counts, but are mentioned in the supplementary documents (supplementary Table 1). Narcology was a common subspecialty of psychiatry during the Soviet era that dealt with the health of people experiencing alcohol and drug use disorders [54,55].

The legacy of the Gulag which incarcerated up to 2 million people still weakens the trust in correctional institutions of former Soviet countries and has ongoing impact on correctional ethics, social networks, and architectural settings in prisons [56]. After the dissolution of the Soviet Union, prison reforms were introduced to humanize living conditions for incarcerated individuals, and to improve the control over the internal organization [57]. Before the implementation of reforms, prisons were organized by subcultures and hierarchies within the prisoner populations that monitored and controlled the other inmates. However, in some regions, levels of violence within the correctional system even increased during reforms. For example,
Georgia, which had one of the highest incarceration rates globally, noted a significant increase in death rates within prisons in 2010, in line with general disorganization, understaffing, and human rights violations. After public awareness of these issues was raised by the media, Georgian authorities declared mass amnesty and in 2013 more than $50 \%$ of the prison population were released [57]. The systematic release of incarcerated people due to presidential clemency was also reported in Turkmenistan [58]. In contrast, Russia had never committed to prison reforms.

In line with a previous study [33], trends of prison population rates were not uniform, but tended towards a mean. Relatively low prison population rates increased, while high rates tended to decrease, reconciling at levels of about 200 per 100000 population. This was in contrast with continuously increasing trends of prison populations in the developing region of Latin America [34]. The observed trends in CEECA were similar to a continuous decrease of the rates of general psychiatric beds and modest increases of forensic and residential psychiatric places as well as prison populations in Western Europe over the last three decades [59].

Complex migration processes $[60,61]$ of the last decades and disputed territories $[62,63]$ might also contribute to the changes of 

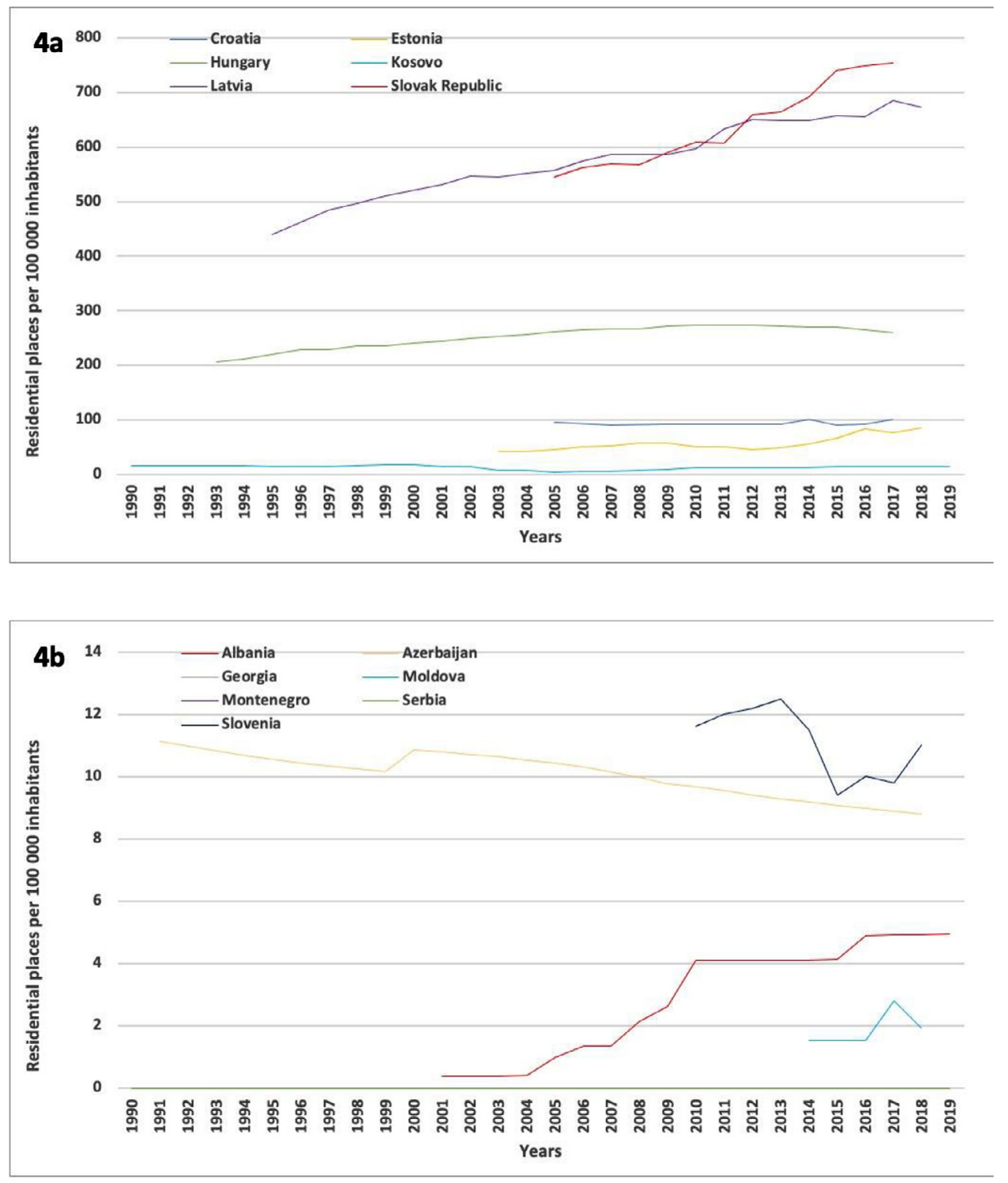

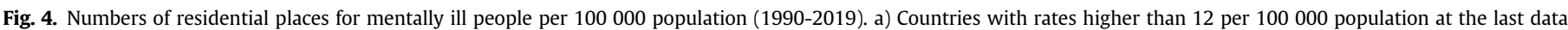

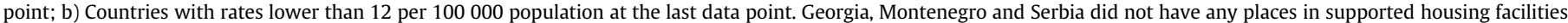
throughout the entire time span.

institutionalization in countries or regions that have undergone armed conflicts or major political changes, such as the Balkan and some of the former-Soviet countries. In the Ukraine, access to data on psychiatric beds and prison populations was no longer available for the occupied territories since 2014.

The majority of countries (57\%) showed inverse trends of decreasing rates of psychiatric beds, while prison population rates increased, in support of the Penrose Hypothesis. However, 12 countries (40\%), among them the most economically challenged, underwent parallel decreases in rates of prison populations and psychiatric beds, in line with the hypothesis presented by Large and Nielssen that poorly resourced governments are not able to pay for any type of custodial service [26]. Kosovo was the only country with increasing trends of both indicators.

Countries that were formerly part of the Soviet Union-who, on average, had lower income levels-showed a greater decrease of psychiatric beds than the other countries in CEECA. Interestingly, the same group of countries also showed a decrease or lower levels of increase regarding prison population rates when compared with higher income economies or non-Soviet countries. One could hypothesize that increasing income levels may have been a driver of prison populations in the region, which would be in line with research from Latin America [32,34].

Previous research has used statistical models to assess associations between the indicators of institutionalization and economic indicators [25,32,34]. Even though such models attempt to resolve uncertainty, the robustness is limited [64,65]. We abstained from using such models of trend analysis, because CEECA countries had very heterogeneous rates at the starting points of the observation period and heterogeneous trends. Furthermore, those analyses cannot bring definitive clarity on causal relationships and may distract from the absolute levels which are most important for service development. Sufficient evidence on the interdependence of correctional systems and psychiatric hospitalization services has been given from studies on individual trajectories and the prevalence rates of mental health problems in prison populations which regularly show that vast majorities are affected. 


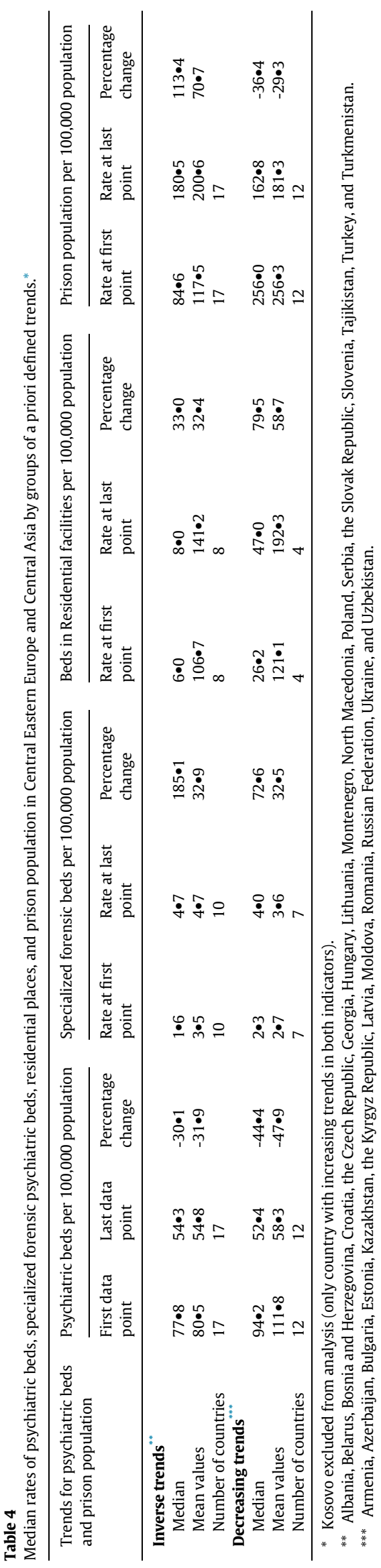

\subsection{Strengths and limitations}

We assessed trends of indicators of institutionalization in 30 countries over three decades, updating previous research on the same indicators from 12 countries over two decades [33]. We retrieved data from primary sources in most participating countries and, therefore, have confidence to present reasonable quality of data.

Limitations of this study are the ecological design and descriptive statistics do not allow to assess associations between indicators. The lack of primary data from five countries of the region, and incompleteness of data for several countries and indicators, were also limitations of the study. Missing data points were common, especially for forensic beds and residential facilities. Secondary sources of data were more frequently necessary for prison populations than for psychiatric beds. The incompleteness of the data limits the comparability of percent changes between countries due to the different observation periods between first and last data points. Considerable difficulties arise from the lack of uniform definitions of psychiatric beds, specialized forensic beds, and places in residential/housing facilities in different countries. Finally, the limited number of data points did not permit more sophisticated time series analyses in countries, such as co-integration analyses, to provide more precise estimates of associations over time.

\subsection{Implications}

Scarcity of data, especially related to mental health, can be a major challenge to service development in the CEECA region specifically, and in LMICs in general [66]. Therefore, internationally standardized data collections on important indicators of institutionalization for mentally ill populations are needed in LMICs such as those in CEECA, in order to internationally compare mental health systems [67]. This will allow countries to see where they need improvement and adopt successful strategies from other regions with similar population demographics and contexts.

There is an overall trend of decreasing rates of psychiatric beds in CEECA. In order to develop public policies to improve mental health services, further research on trends and targets for psychiatric bed numbers is required. Prison population rates did not show any uniform trends, although they tended to increase in countries with lower rates and decrease in countries with higher rates, indicating a regression towards the mean. Historical, societal, and political factors that may influence healthcare decision making, and therefore changes in rates, need to be further explored. Mechanisms for a possible interdependence of psychiatric bed numbers and prison population rates in CEECA should be further investigated on the country level or based on subgroups of countries. In addition to the assessment of static measures of psychiatric bed numbers and prison populations, the dynamic data, such as admissions to the institutions can provide further information on a possible interdependence of the systems [68].

Consensus on how many psychiatric beds mental health systems need has not yet been reached and normative approaches have been proposed to provide orientation [69]. An alternative is to observe possible outcomes using key performance indicators and population outcomes, in order to estimate the bed requirements based on those indicators [70]. Among the outcomes could be the rates of prison populations and their trends.

All the forms of institutionalized care assessed in this study come with considerable costs to societies and have substantial consequences for the many people who are directly or indirectly affected. Thus, it should be in the interest of all countries to have policies that are as appropriate and effective as possible. For developing such policies, a comparison of data across countries that are in a similar historical context must be a useful step. In this case, our comparison revealed 


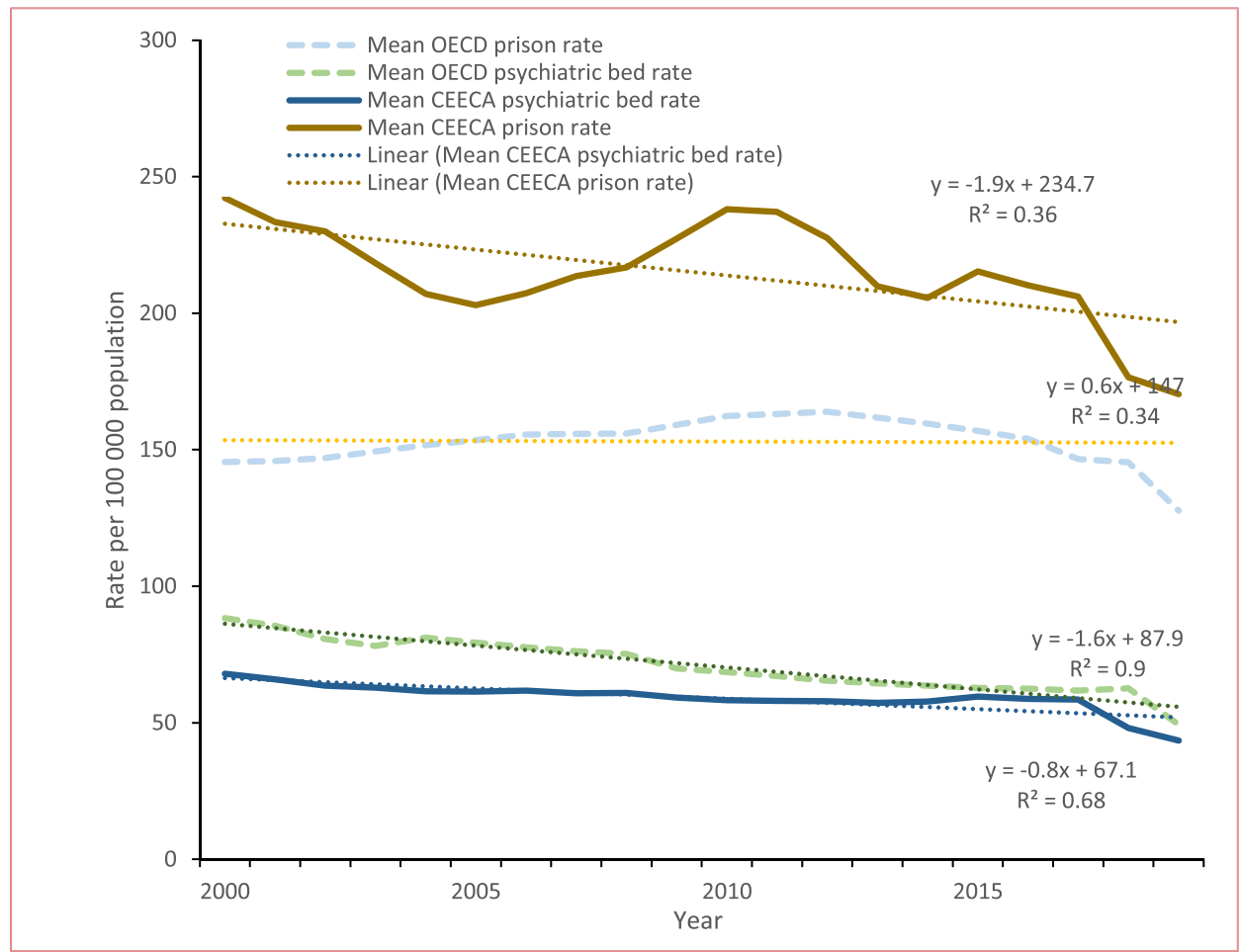

Fig. 5. Mean psychiatric bed and prison population rates in Central and Eastern European and Central Asian Countries compared with OECD countries.

major differences which may facilitate both more detailed and reliable data recording and learning from each other.

\section{Contributors}

APM conceptualization, project administration, funding acquisition, supervision and validation. VA, FI, YER, MH, TF, PC, JH, GG, MPK, MA, SN, NFI, EM, MT, JC, JD, PG, NT, AG, DLT, DR, LI, VŠ, MV, NK and OS investigation, data curation, methodology, writing - review \& editing. APM, ERS, MS and SP methodology, software, writing - original draft, writing - review \& editing.

\section{Declaration of Competing Interests}

We declare no competing interests.

\section{Acknowledgments}

This study was funded by the Agencia Nacional de Investigación y Desarrollo ANID, grant scheme FONDECYT Regular, grant number 1190613.

\section{Data sharing statement}

A complete database of all indicators and countries is available in the supplement 1 .

\section{Supplementary materials}

Supplementary material associated with this article can be found, in the online version, at doi:10.1016/j.lanepe.2021.100137.

\section{References}

[1] Whiteford HA, Degenhardt L, Rehm J, et al. Global burden of disease attributable to mental and substance use disorders: findings from the Global Burden of Disease Study 2010. Lancet 2013;382(9904):1575-86.

[2] WHO. Suicide data. World Health Organization; 2019

[3] WHO. Mental health atlas project. World Health Organization; 2001.

[4] WHO. Global status report on alcohol and health 2018. World Health Organization; 2018.

[5] Peacock A, Leung J, Larney S, et al. Global statistics on alcohol, tobacco and illicit drug use: 2017 status report. Addiction 2018;113(10):1905-26.

[6] Formanek T, Kagstrom A, Winkler P, Cermakova P. Differences in cognitive performance and cognitive decline across European regions: a population-based prospective cohort study. Eur Psychiatry 2019;58:80-6.

[7] Horackova K, Kopecek M, Machu V, et al. Prevalence of late-life depression and gap in mental health service use across European regions. Eur Psychiatry 2019;57:19-25.

[8] Pridemore WA. Change and stability in the characteristics of homicide victims offenders and incidents during rapid social change. Br J Criminol 2007;47 (2):331-45.

[9] Altice FL, Azbel L, Stone J, et al. The perfect storm: incarceration and the high-risk environment perpetuating transmission of HIV, hepatitis $C$ virus, and tuberculosis in Eastern Europe and Central Asia. Lancet 2016;388(10050):1228-48.

[10] Walmsley R. World prison population list. The Institute for Criminal Policy Research (ICPR) at Birkbeck, University of London; 2018.

[11] Baranyi G, Cassidy M, Fazel S, Priebe S, Mundt AP. Prevalence of posttraumatic stress disorder in prisoners. Epidemiol Rev 2018;40(1):134-45.

[12] Baranyi G, Scholl C, Fazel S, Patel V, Priebe S, Mundt AP. Severe mental illness and substance use disorders in prisoners in low-income and middle-income countries: a systematic review and meta-analysis of prevalence studies. Lancet Glob Health 2019;7(4):e461-e71.

[13] Fazel S, Yoon IA, Hayes AJ. Substance use disorders in prisoners: an updated systematic review and meta-regression analysis in recently incarcerated men and women. Addiction 2017;112(10):1725-39.

[14] Lovett A, Kwon HR, Kidia K, et al. Mental health of people detained within the justice system in Africa: systematic review and meta-analysis. Int J Ment Health Syst 2019;13:31.

[15] Mundt AP, Alvarado R, Fritsch R, et al. Prevalence rates of mental disorders in Chilean prisons. PLoS One 2013;8(7):e69109.

16] Almanzar S, Katz CL, Harry B. Treatment of mentally ill offenders in nine developing Latin American countries. J Am Acad Psychiatry Law 2015;43(3):340-9.

[17] Vagenas P, Azbel L, Polonsky M, et al. A review of medical and substance use comorbidities in Central Asian prisons: implications for HIV prevention and treatment. Drug Alcohol Depend 2013;132(Suppl 1):S25-31.

[18] Golrokhi R, Farhoudi B, Taj L, et al. HIV Prevalence and correlations in prisons in different regions of the world: a review article. Open AIDS J 2018;12:81-92. 
[19] Baillargeon J, Binswanger IA, Penn JV, Williams BA, Murray OJ. Psychiatric disorders and repeat incarcerations: the revolving prison door. Am J Psychiatry 2009:166(1):103-9.

[20] Mundt AP, Kastner S, Mir J, Priebe S. Did female prisoners with mental disorders receive psychiatric treatment before imprisonment? BMC Psychiatry 2015;15:5.

[21] Birmingham L. Between prison and the community. the 'revolving door psychiatric patient' of the nineties. Br J Psychiatry 1999;174:378-9.

[22] Mundt AP, Baranyi G. The unhappy mental health triad: comorbid severe menta illnesses, personality disorders, and substance use disorders in prison populations. Front Psychiatry 2020;11:804.

[23] Penrose L. Mental disease and crime: outline of a comparative study of European statistics. Br J Med Psychol 1939;18:1-15.

[24] Kalapos MP. Penrose's law: methodological challenges and call for data. Int J Law Psychiatry 2016;49(Pt A):1-9.

[25] Blüml V, Waldhor T, Kapusta ND, Vyssoki B. Psychiatric hospital bed numbers and prison population sizes in 26 European Countries: a critical reconsideration of the Penrose hypothesis. PLoS One 2015;10(11):e0142163.

[26] Large MM, Nielssen O. The Penrose hypothesis in 2004: patient and prisoner numbers are positively correlated in low-and-middle income countries but are unrelated in high-income countries. Psychol Psychother 2009;82(Pt 1):113-9.

[27] Hartvig P, Kjelsberg E. Penrose's law revisited: the relationship between mental institution beds, prison population and crime rate. Nord J Psychiatry 2009;63 (1):51-6.

[28] Priebe S, Frottier P, Gaddini A, et al. Mental health care institutions in nine European countries, 2002 to 2006. Psychiatr Serv 2008;59(5):570-3.

[29] Abramowitz M, Grinshpoon A, Priebe S, Ponizovsky AM. New institutionalization as a rebound phenomenon? The case of Israel. Isr J Psychiatry Relat Sci 2008;45 (4):272-7

[30] Steadman HJ, Monahan J, Duffee B, Hartstone E, Robbins PC. The impact of state mental hospital deinstitutionalization on United States prison populations, 1968-1978. J Criminal Law Criminol 1984;75(2):474-90.

[31] Biles D, Mulligan G. Mad or bad?-the enduring dilemma. Br J Criminol 1973;13 (3):275-9.

[32] Mundt AP, Chow WS, Arduino M, et al. Psychiatric hospital beds and prison populations in South America since 1990: does the Penrose hypothesis apply? JAMA Psychiatry 2015;72(2):112-8.

[33] Mundt AP, Franciskovic T, Gurovich I, et al. Changes in the provision of institutionalized mental health care in post-communist countries. PLoS One 2012;7(6): e38490.

[34] Siebenförcher M, Fritz FD, Irarrázaval M, et al. Psychiatric beds and prison populations in 17 Latin American countries between 1991 and 2017: rates, trends and an inverse relationship between the two indicators. Psychol Med 2020:1-10. doi: 10.1017/s003329172000269x.

[35] Poloshij B, Saposhnikova. Psychiatric reform in Russia. Acta Psychiatr Scand Suppl 2001(410):56-62.

[36] van Voren R. Psychiatry as a tool for coercion in post-soviet countries. European Parliament's Subcommitee on Human Rights. Policy Department DG External Policies - European Union; 2013.

[37] Tomov T, Van Voren R, Keukens R, Puras D. Mental health policy in former eastern bloc countries. Mental health policy and practice across Europe - European Observatory on Health Systems and Policies Series; 2006.

[38] Fleming PM. Substance misuse services in the USSR. Psychiatr Bull 2018;15 (11):689-91.

[39] Winkler P, Krupchanka D, Roberts T, et al. A blind spot on the global mental health map: a scoping review of 25 years' development of mental health care fo people with severe mental illnesses in central and Eastern Europe. Lancet Psychiatry 2017;4(8):634-42.

[40] Furedi J, Mohr P, Swingler D, et al. Psychiatry in selected countries of Central and Eastern Europe: an overview of the current situation. Acta Psychiatr Scand 2006;114(4):223-31

[41] Krasnov V, Bokhan N. Russian Federation from: Routledge handbook of psychiatry in Asia Routledge. 2015.

[42] Winkler P, Formanek T, Mlada K, Cermakova P. The CZEch Mental health Study (CZEMS): Study rationale, design, and methods. Int J Methods Psychiatr Res 2018;27(3):e1728

[43] WHO. Mental health atlas 2017. World Health Organization; 2018

[44] Barbato A, Civenti G, D'Avanzo B. Community residential facilities in mental health services: a ten-year comparison in Lombardy. Health Policy 2017;121(6):623-8.
[45] Macpherson R, Sheperd G, Thyarappa P. Supported accommodation for people with severe mental illness: an update. Adv Psychiatr Treat 2012;18:381-91.

[46] WHO. European Health Information Gateway - Number of psychiatric hospital beds. 17 October 2019. https://gateway.euro.who.int/en/indicators/hfa_4895071-number-of-psychiatric-hospital-beds/ (accessed 20 July 2020).

[47] World Prison Brief - Institute for Crime \& Justice Policy Research. 2019 www.prisonstudies.org.

[48] WorldBank. https://data.worldbank.org/2019.

[49] Sarioglo V.D.D., Pacera C., Danyuk M., Chertov O., Polikarchuk P. Estimated number of the current population of Ukraine - detailed to the level of regions - as of december 1, 2019. 2019. http://www.ukrstat.gov.ua/Noviny/new2020/zmist/ novini/OnU_01_12_2019.pdf (accessed October 28, 2020).

[50] Torrey EF, Entsminger K, Geller J, Stanley J, Jaffe DJ. The shortage of Public Hospital Beds for Mentally Ill Persons. Arlington, USA: The Treatment Advocacy Center; 2008.

[51] Allison S, Bastiampillai T, Licinio J, Fuller DA, Bidargaddi N, Sharfstein SS. When should governments increase the supply of psychiatric beds? Mol Psychiatry 2018:23(4):796-800.

[52] Okasha A, Karam E. Mental health services and research in the Arab world. Acta Psychiatr Scand 1998;98(5):406-13.

[53] Okasha A, Karam E, Okasha T. Mental health services in the Arab world. World Psychiatry 2012;11(1):52-4.

[54] Elovich R, Drucker E. On drug treatment and social control: Russian narcology's great leap backwards. Harm Reduct J 2008;5:23.

[55] Latypov AB. The Soviet doctor and the treatment of drug addiction: "a difficult and most ungracious task". Harm Reduct J 2011;8:32.

[56] Slade G, Light M. Crime and criminal justice after communism: why study the post-Soviet region? Theor Criminol 2015;19(2):147-58.

[57] Slade G. Violence as information during prison reform: evidence from the postsoviet region. Br J Criminol 2016;56(5):937-55.

[58] Turkmenistan TSNAo. 2028 convicted persons released in honour of the National Spring Festivities (Nowruz) Published online on 24 March 2019 by Turkmen State News Agency 2019.

[59] Chow WS, Priebe S. How has the extent of institutional mental healthcare changed in Western Europe? Analysis of data since 1990. BMJ Open 2016;6(4): e010188.

[60] Grzymała-Kazłowska A. Migration and socio-demographic processes in Central and Eastern Europe: characteristics, specificity and internal differences. Central East Eur Migr Rev 2013;2(1) Central and Eastern European Migration Review 2013; 2: $5-11$

[61] Bonifazi C, Mamolo M. Past and current trends of Balkan migrations. Espace Populations sociétés 2004;2004/3:519-31.

[62] Legucka A. Frozen and freezing conflicts in Eastern Europe and South Caucasus: implications for regional security. Yearbook of the Institute of East-Central Europe (Rocznik Instytutu Europy Środkowo-Wschodniej) 2017;15:79-97.

[63] Rabinovych M. The domestic dimension of defining uncontrolled territories and its value for conflict transformation in Moldova, Georgia, and Ukraine. In: Shelest H, Rabinovych M, editors. Decentralization, regional diversity, and conflict: the case of Ukraine. Cham: Springer International Publishing; 2020. p. 107-43.

[64] Tsai AC, Venkataramani AS. A more robust test of the Penrose hypothesis. JAMA Psychiatry 2015;72(7):735-6.

[65] Mundt AP, Chow WS, Priebe S. Testing the Penrose hypothesis-reply. JAMA Psychiatry 2015;72(7):736

[66] Lora A, Hanna F, Chisholm D. Mental health service availability and delivery at the global level: an analysis by countries' income level from WHO's Mental Health Atlas 2014. Epidemiol Psychiatr Sci 2020;29:e2.

[67] Wainberg ML, Scorza P, Shultz JM, et al. Challenges and opportunities in global mental health: a research-to-practice perspective. Curr Psychiatry Rep 2017;19 (5):28.

[68] O'Neill CJ, Kelly BD, Kennedy HG. A 25-year dynamic ecological analysis of psychiatric hospital admissions and prison committals: Penrose's hypothesis updated. Ir J Psychol Med 2018:1-4.

[69] Pirkis J, Harris M, Buckingham W, Whiteford H, Townsend-White C. International planning directions for provision of mental health services. Admin Policy Mental Health Mental Health Serv Res 2007;34(4):377-87.

[70] O'Reilly R, Allison S, Bastiampiallai T. Observed outcomes: an approach to calculate the optimum number of psychiatric beds. Adm Policy Ment Health 2019;46 (4):507-17 